\title{
Theory of Reasoned Action as an Underpinning to Technological Innovation Adoption Studies
}

\author{
Odoyo Collins Otieno ${ }^{1, *}$, Samuel Liyala ${ }^{1}$, Benson Charles Odongo ${ }^{2}$, Silvance Abeka $^{1}$ \\ ${ }^{1}$ School of Informatics and Innovative Systems, Jaramogi Oginga Odinga University of Science and Technology, Kenya \\ ${ }^{2}$ Department of Special Needs Education and Early Childhood Development, Jaramogi Oginga Odinga University of Science and \\ Technology, Kenya
}

Copyright $\mathrm{C} 2016$ by authors, all rights reserved. Authors agree that this article remains permanently open access under the terms of the Creative Commons Attribution License 4.0 International License

\begin{abstract}
There are a number of theories and models that have been employed over the years in understanding and studying users' technology adoption behaviors. These theories and models focus on people's intention to engage in a certain behavior such as the adoption and use of new technologies. The Theory of Reasoned Action (TRA) is one of such theories that have been widely used in technology adoption as well as used in a number of other research fields as a foundation to such studies. Most of the Information Systems scholars, who have used this theory, have used only to set a foundation or help build other theories and models. TRA has therefore been compared with other theories and models for technological innovation, and found to be a strong theory for innovation adoption upon a few additions of other variables such as facilitating conditions, awareness of innovation by users, social pressure and user readiness.
\end{abstract}

Keywords Theory of Reasoned Action, TRA, Technology Acceptance Model, TAM, Theory of Planned Behaviour, TPB, and Innovation

\section{Introduction}

Theory of Reasoned Action (TRA) was formulated by Ajzen and Fishbein [1]. This resulted from attitude research using the Expectancy Value Models [2]. The formulation came forth after trying to estimate the discrepancy that existed between attitude and behavior. The fundamentals of the TRA come from the field of social psychology. Social psychologists attempt, among other things, to explain how and why attitude affects behavior, which is equally very important in mirroring this study. That is, how and why people's beliefs change the way they act. Behavior can either be verbal or non-verbal such as body language, signals, signs, or vocally expressed. Psychologists argued about what should make up the term attitude. Social psychologists suggest that attitude includes behavior and cognition, and that attitude and behaviors are positively correlated. This is the reason why Theory of Reasoned Action is well placed in conducting studies on technological innovation.

\section{Literature Review}

TRA was formulated by Ajzen and Fishbein [1]. It resulted from attitude research using the Expectancy Value Models [2]. The formulation of TRA was after trying to estimate the discrepancy that existed between attitude and behavior. The fundamentals of the TRA come from the field of social psychology. Social psychologists attempt, among other things, to explain how and why attitude affects behavior, which is equally very important in mirroring this study. That is, how and why people's beliefs change the way they act. The study will look at how attitude and beliefs affect the utilization of mobile phone money. Behavior can either be verbal or non-verbal such as body language, signals, signs, or vocally expressed. TRA put forth three general constructs namely: (1) behavioral intention, (2) attitude, and (3) subjective norm.

TRA has been tested in numerous studies across many disciplines and cases including dieting, using condoms, consuming genetically engineered foods and limiting sun exposure [3]. The theory can be extended to conceptualize the human behavioral pattern in the decision-making strategy on the utilization of a new innovation or technology. It is capable of explaining whether individual behavior such as utilization of new innovation is driven by behavioral intentions, where behavioral intentions is a function of an individual's attitude toward the behavior, the subjective norms surrounding the performance of the behavior, and the individual's perceptions of the ease with which the behavior can be performed. The theory has not extensively been utilized in evaluating studies such as technology adoption and diffusion. In the Information Systems literature, this theory has only been used in identifying users' behaviors and attitudes in issues relating to Internet use, online purchase, household computer use, and online privacy, security, and trust [4]. Social 
psychologists suggest that attitude includes behavior and cognition, and that attitude and behavior is positively correlated, giving the reason for applying TRA in understanding mobile phone money utilization. From the review of relevant literature, most of the existing research on the subject of consumer adoption of mobile phone money is based on TAM. Studies that have used Theory of Reasoned Action (TRA) and Theory of Planned Behaviour (TPB) are very few, and have only been used to an extent where they set up the stage for other theories such as TAM, Extended TAM, and Unified Theory of Acceptance and Use of Technology (UTAUT). TRA is sufficient in guiding consumers' utilization of new innovations and technology, leading to its adoption for this study, to bring forth the strength of this theory in understanding and Information Systems discourse.

A study by Wei, Xinyan, and Yue [5] to review prior literature on mobile commerce, analyses the various adoptive factors, and suggests future research direction. Their study followed a method where they conducted an exhaustive and systematic electronic search of 59 articles, 23 Chinese and 36 English. Their study was further, based upon research subjects; research theory; and adoptive factors. They established that most of the existing studies were on the subject of consumer adoption; and TAM was the most-used theory in consumer adoption. They also established that, the majority of adoptive factors are characteristics of mobile commerce service providers, mobile commerce merchants, mobile commerce consumers, and the environment; consumer perception features of mobile commerce. It was established further that very few studies have used social psychology based theories such as Theory of Reasoned Action or Theory of Planned Behavior. The two theories have been used sparingly in Information Systems studies even though they do have a better platform in studying adoption of new innovations and technology based on behavioral intentions as well as subjective norms and social influence.

Liker and Sindi [6], in their paper developed and tested a model based on the TRA in order to understand the challenges posed by expert systems on management. The model was tested using a cross-sectional design based on a self-administered questionnaire completed by a sample of 94 users and non-users from two of the largest accounting firms in the U.S. The outcome measures were attitudes toward the system and intentions to use the system in the future (or continue to use it among existing users). The results supported several hypotheses. Intentions to use the system were influenced by social norms encouraging system use and by perceptions of the impacts of system use on valued skills, controlling for the effect of attitudes. Attitudes toward use of the system were affected by the perceived usefulness of the system and its impacts on valued skills. Attitudes were also strongly related to ease of system use, an unanticipated finding. The most surprising result was that general attitudes were not found to predict intentions to use the system. The data showed no evidence of fearful reactions of employees to Expert Systems in this particular context. The study discussed the implications for user acceptance of expert systems, and how results compare to those of other information technologies. However, the practical implication dwelt more on Expert Systems and related systems to Expert Systems.

Teo and Pok [7] in their paper examined the factors influencing the adoption of Wireless Application Protocol (WAP) - enabled mobile phones among Internet users. This study used theory of reasoned action, theory of planned behaviour, technology acceptance model, and innovation diffusion theory as a theoretical basis, since it attempted to explain intention of certain behaviour and adoption of certain technology. The study established that, it is attitudinal factors and subjective norms, rather than perceived behavioral control that influence intention to use a WAP enabled mobile phone. To be specific, perception of relative advantage, risk and image were found to influence adoption intentions. Teo and Pok [7], also examined the effect of compatibility on the usage intentions when forum sample and e-mail sample was used. They found out that compatibility for e-mail sample had a significant effect on the usage intention indirectly through attitude. This study also confirmed that theory of reasoned action has been used in support of other theories. Many researchers who apply theory of reasoned action in studying technology adoption related studies, have constantly used it to support other theories such as TAM, TPB, and Innovation Diffusion Theory. This is why this study will only apply theory of reasoned action in studying Mobile Phone Users' Perception on Mobile Phone Money Utilization.

There are a number of theories and models that have been employed over the years in understanding and studying individuals' technology adoption behaviors. These theories and models focus on people's intention to engage in a certain behavior such as the adoption and use of new technologies. The Theory of Reasoned Action (TRA) (1980) has been widely used in technology adoption as well as used in a number of research fields as a foundation to such studies.

Information technology adoption and utilization in the workplace and our society in general remains a central concern of information systems research and practice. Therefore, understanding and creating the conditions under which information systems are embraced by the human organization remains a high-priority research issue.

Theory of Reasoned Action is a series of related concepts and hypotheses postulated by social psychologists to understand and to predict human behavior [8]. TRA has developed from the long standing collaborative research conducted by renowned psychologists Fishbein and Ajzen [1]. This resulted from attitude research using the Expectancy Value Models [2]. They did this formulation of TRA after trying to estimate the discrepancy that existed between attitude and behavior. From the onset of TRA in behavioral research, it has been applied to study a wide variety of situations and is now regarded as one of the most influential theories about volitional human behavior [9]. It is based on the assumption that human beings usually behave in a sensible manner, as the name of the theory implies; that 
is, they take account of available information and consider the implications of their actions. The theory postulates that a person's intention to perform or not to perform a behavior is the immediate determinant of that action; barring unforeseen events, people are expected to act in accordance with their intentions. Intention to adopt mobile phone money in rural communities can also be seen to depend on the users' volitional behavior. Mobile phone users take account of the available information about mobile phone money and consider implications of adopting or not adopting. The information considered may be the cost implications, availability of support services, technical knowledge required to be able to adopt the technology, alternative ways of achieving the services offered by mobile phone money.

"The stronger the intention to adopt mobile phone money, the more the person is expected to try applying this technology, and therefore the greater the possibility that the behavior will actually be performed, and thus the primary concern is with identifying the factors underlying the formation and change of behavioral intent" [10]. A person's intention to behave in a certain way is based on: their 'attitude' toward the behavior in question and their perception of the social pressures on them to behave in that way, that is, 'subjective norms'. The relative contribution of attitudes and subjective norms varies according to the behavioral context and individual involved. Attitudes are determined by the beliefs about the outcomes of performing the behavior and the evaluation of these expected outcomes. The subjective norm is dependent on beliefs about how others feel the individual should behave and their motivation to comply with these expectations from others [1]. Most of the mobile phone users embrace social coexistence. Because of this every action they do, they consider or evaluate how such actions will affect their colleagues. They look at how positively or negatively, their actions will affect other community members.

Social psychologists attempt, among other things, to explain how and why attitude affects behavior, which is equally very important in mirroring this study. That is, how and why people's beliefs change the way they act. The study will be looking at how attitude and beliefs affects the utilization of mobile phone money. Behavior can either be verbal or non-verbal such as body language, signals, signs, or vocally expressed.

TRA therefore, put forth three general constructs namely: (1) behavioral intention, (2) attitude, and (3) subjective norm. Ajzen and Fishbein [1] states that a person's behavior is determined by the person's intention to perform that behavior and that; this intention is, in turn, a function of the person's attitude toward the behavior. One of the potential reflectors of possible behavioral outcome is intention. Intention is the cognitive representation of a person's readiness to perform an intended behavior, and is considered an immediate indicator of behavior. Behavioral intention measures the relative strength of a person's likelihood to perform an anticipated behavior. This includes motivational or attitudinal factors that capture how individuals are engaging to perform the intended behavior [4]. Subjective norm on the other hand is regarded as a combination of perceived expectations from relevant individuals along with the intention to comply with such expectations [11]. A person's attitude, combined with subjective norms, forms the person's behavioral intention. Thus, behavioral intention is a function of both attitudes toward a behavior and subjective norms toward that behavior, which can then predict the actual behavior.

TRA can therefore be extended to conceptualize the human behavioral pattern in the decision-making strategy on the utilization of a new innovation or technology. It is capable of explaining whether individual behavior such as utilization of new innovation is driven by behavioral intentions, where behavioral intentions is a function of an individual's attitude toward the behavior, the subjective norms surrounding the performance of the behavior, and the individual's perceptions of the ease with which the behavior can be performed (behavioral control). Further, TRA has not extensively been utilized in evaluating studies such as technology adoption and diffusion in the field of Information Systems and ICT in general.

Psychologists further, argued about what should make up the term attitude. Social psychologists suggest that attitude includes behavior and cognition, and that attitude and behaviors are positively correlated. This is the reason why this study applies Theory of Reasoned Action in understanding mobile phone money utilization. Mobile phone money utilization is a matter of attitude towards it. The users only adopt and engage only that technology they perceive to have value to them. Further, from the review of relevant literature, most of the existing researches on the subjects of consumer adoption of mobile phone money are based on TAM. Studies that have attempted to use Theory of Reasoned Action and Theory of Planned Behaviour (TPB) are very few, and have only used TRA and TPB, to an extent where they set up the stage for other theories such as TAM, Extended TAM, and Unified Theory of Acceptance and Use of Technology (UTAUT). However, TRA is sufficient in guiding consumers' utilization of new innovations and technology. This further give ground for using purely TRA in this study, to bring forth the strength of this theory in understanding and Information Systems discourse.

Since the theory of Reasoned Action can also be used in technology adoption and general research as a fundamental theoretical framework, this study finds it important in guiding the research process in Information Systems. Attitude and subjective norm have been found to be important determinants of peoples' intentions to perform an action such adopting and using new technology [12]. Attitude is having a significant influence on the intention to adopt and continue to use technology [13]. That is the main reason why this study will be based on TRA. These relationships are summarized in Figure 1. 


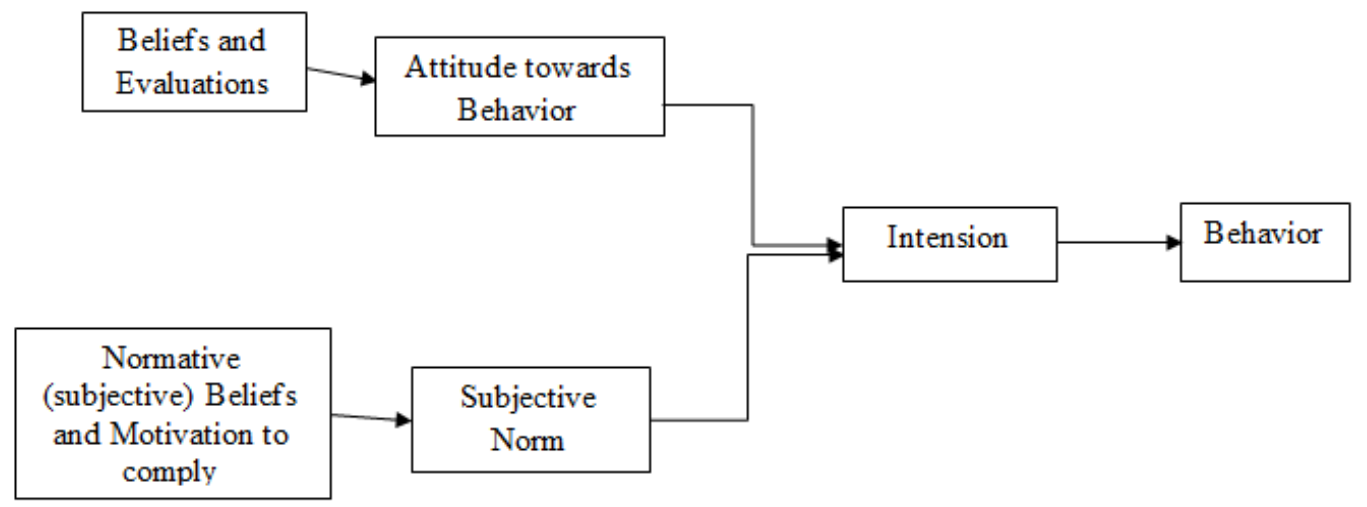

Figure 1. Theory of Reasoned Action. Source: Fishbein, \& Ajzen (2010)

\section{Materials and Methodology}

Qualitative research technique was used because of its appropriateness in understanding this paper, is based on the perceptions of mobile phone money users as well as potential user that are qualitative in nature. Further, only secondary data was used, that were generated from literature of studies that had been done by other scholars. Being a paper that looked at the suitability of a theory to the field of information systems, specifically technological innovation adoption, it was very important to compare it with other theories and models used in the same field in terms of strength and weakness.

\section{Discussions}

Theory of Reasoned Action was established to be very appropriate in guiding Information Systems studies, especially those that deals with technological innovation adoption. To clearly bring this fact out, it was important to critically look at its strength in technological innovation studies alongside other theories that have been applied over the years by other scholars in the field, such TAM, TAM2, DOI, TOE, and UTAUT among others.

To begin with, Technology Acceptance Model (TAM) is the most cited theory in many studies on Information Systems as well as general ICT with respect to adoption of a new innovation. Davis [14] presented this theoretical model aiming to predict and explain ICT usage behavior, that is, what causes potential adopters to accept or reject the use of information technology. Theoretically, TAM is based on the TRA as a foundation. TAM put forth, two theoretical constructs namely perceived usefulness and perceived ease of use which are the fundamental determinants of system use, and predict attitudes toward the use of the system, that is, the user's willingness to use the system. Perceived usefulness refers to "the degree to which a person believes that using a particular system would enhance his or her job performance", and perceived ease of use refers to "the degree to which a person believes that using a particular system would be free of effort" [14]. Venkatesh and Davis
[15] later developed and tested a theoretical extension of TAM and referred to it as TAM2, which explains perceived usefulness and usage intentions with the help of social influence and cognitive instrumental processes.

The reasons for the popularity of TAM as the theoretical framework is that, TAM is a theory specifically developed for ICT implementation and adoption research. It is a theory owned by the IS research community, a field, in which theories are scarce [16]. TAM provides a clear and tested framework for ICT adoption and implementation research [17]. The other strength of TAM is its simplicity [14], which has been achieved by leaving social and organizational factors outside the scope of the theory.

On the other hand, looking at the weaknesses, TAM has left out social and organizational factors in its construct, which are very instrumental in influencing technological innovation and ICT adoption. Also, extending TAM to achieve other variations of TAM such TAM2 or other different models and independent variables may cause a theoretical confusion in which, it may become unclear which version of the many iterations of TAM is the commonly accepted one [18]. Also, the many extensions of TAM did not succeed in deepening the theory in the sense of explaining the essential concepts in greater depth [19], for example, by explaining exactly what perceived usefulness or ease of use means [20]. This is the reason why this study found TAM and its extension unsuitable.

The next theory that has widely been cited was the Diffusion of Innovations (DOI). DOI is a theory of how, why, and at what rate new ideas and technology spread through cultures, operating at the individual and firm level. Innovations are viewed as being communicated through certain channels over time and within a particular social system [21]. On the other hand, individuals are seen to possess a different degree of willingness to adopt innovations, and thus, it is generally observed that the portion of the population adopting an innovation is normally distributed over time [21]. This gives a distribution ranging from earliest to latest adopters, namely; innovators, early adopters, early majority, late majority, laggards [21].

The innovation process in organizations seems to be much more complex, and involves a number of individuals, 
including both supporters and opponents of the new idea, each of whom plays a role in the innovation-decision. Based on DOI theory at firm level, innovativeness is related to independent variables such as individual/leader characteristics, internal organizational structural characteristics, and external characteristics of the organization [21]. DOI theory is quite relevant in study the process of adopting new technology. It covers a wide range of scope, looking at the influence made by an individual (a leader), internal conditions as well as external conditions. However much these factors are important as proposed by Rogers, they only apply effectively in the context of an organization, or a society that is so much enclosed with a strong figurehead or leader, who has much influences on the technologies being used by the society members.

Homa Bay region where this study was conducted, with a population that has got free will on whether or whether not to adopt technological innovation, and further being an area having both the poor and wealthy, the educated and uneducated, DOI theory becomes inappropriate. The area is also a community and not an organization and as such do not have the characteristics of an organization, with features of influence from individual (a leader), internal characteristics and external characteristics. DOI further looks at the process of adoption over period of time, in five stages namely innovators, early adopters, early majority, late majority, laggards, which is quite important, but not sufficient to conduct a study on technology adoption/acceptance. This theory cannot be complete as a good theory without looking at social influence, facilitating conditions, motivation to comply as well as awareness of the user on new technology.

The Technology, Organization, and Environment context (TOE) framework was developed in 1990 [22]. This framework has also been used in understanding technological innovation adoption and is more suited to the context of an enterprise. It identifies three aspects of an enterprise's context that influence the process by which it adopts and implements a technological innovation namely; technological context, organizational context, and environmental context. Technological context describes both the internal and external technologies relevant to the firm, which includes current practices and equipment internal to the firm [23], as well as the set of available technologies external to the firm [24]. Organizational context on the other hand, refers to descriptive measures about the organization such as scope, size, and managerial structure. While Environmental context, is the arena in which a firm conducts its business and include aspects such as; its industry, competitors, and dealings with the government [22]. This framework just as DOI theory focusses more on an organization or an enterprise. It is more relevant when looking at factors influencing adoption of a technological innovation at the level of an enterprise, but becomes inappropriate when looking at adoption of technological innovation at a wider community/society level. It also fails to look at important factors such as social influence, facilitating conditions, motivation to comply as well as awareness of the new technology.

The next theory that has been heavily used in understanding technological innovation adoption is the Theory of Planned Behavior (TPB). This theory was presented by Ajzen [4] and it focuses on cognitive self-regulation. It is very similar to the TRA model, but the difference is that it takes into account an additional construct, namely perceived behavioral control. Perceived behavioral control refers to the perception of control over the performance of a given behavior. This theory is very similar to TRA in many aspects, except in the addition of perceived control. Since TRA already captures factors such as personal attitudes and social pressure, other factors that are key that are missing in TRA have still been left out by TPB. Even though TPB stands out in addressing adoption of technological innovation over TAM, DOI and TOE in varied situation such as community/society or organization, since it focusses on the user or potential user, it still has a missing link of facilitating conditions, awareness of new technology and community/user readiness as other factors. Perceived control with TPB adds in addition the other scope covered by TRA may be insignificant in influencing technological innovation adoption. This therefore means TRA, with a few modification would be conducive in understanding technological innovation adoption in whatever context.

The other theory that had been widely used and cited was the Unified Theory of Acceptance and Use of Technology (UTAUT). Venkatesh, Morris, Davis, and Davis (2003) developed the unified model through reviewing other models which explain ICT usage, namely TRA, TAM, the motivational model, TPB, a model combining TAM and TPB, the model of PC utilization, DOI, and the social cognitive theory. UTAUT was mainly to explain the user's intentions to use technological innovation and a subsequent user behavior. The model considers four constructs as direct determinants of user acceptance and usage behavior, namely performance expectancy, effort expectancy, social influence, and facilitating conditions. Also, there are four key moderating variables namely; gender, age, experience, and voluntariness of use. However, UTAUT, being an extension and combination of other theories and models try to respond to the challenge of contextuality by adding new independent variables, such as individual characteristics (gender, motivation etc.), situational variables (experience, training etc.), or organizational characteristics (subjective norms). These extensions however, have since led, to some other challenges. To begin with, the extensions and combinations caused a crowed of variables, leading to the theory losing its strength. This led to the theory becoming weaker in its clarity [25]. UTAUT has 41 independent variables for predicting intentions and eight independent variables for predicting behavior [20]. This challenge of too many variables is the main reason why this study failed to adopt UTAUT.

The TRA other than being selected as the basis of this study has been mostly cited in Information Systems and ICT studies, but mainly to an extent where it set a stage for other 
theories like TPB and TAM. This theory originates from social psychology, and other people take it as a special case of the TPB [26]. Fishbein and Ajzen [11] developed TRA to define the links between the beliefs, attitudes, norms, intentions, and behaviors of individuals. TRA assumes that a person's behavior is determined by the person's behavioral intention to perform it, and the intention itself is determined by the person's attitudes and his or her subjective norms towards the behavior. The subjective norm refers to the person's perception that most people who are important to him think he should or should not perform the behavior in question [11].

This theory was introduced in an effort to understand the relationship between attitude and behaviour. It attempts to explain the relationship between beliefs, attitudes, intentions and behaviour. According to TRA, the most accurate determinant of behaviour is behavioural intention. The direct determinants of people's behavioural intentions are their attitudes towards performing the behaviour and the subjective norms associated with the behaviour. Attitude is determined by a person's beliefs about the outcomes or attributes of performing a specific behaviour, weighted by evaluations of those outcomes or attributes. The subjective norm of a person is determined by whether important referents approve or disapprove of the performance of a behaviour (that is, normative beliefs), weighted by the person's motivation to comply with those referents [27].

Having established TRA as a better theory for this study, over other theories, especially considering the determinants of behaviour, a few determinants of behaviour can be incorporated to make it better. To make TRA even more conducive for a study similar to this, there is need to incorporate other direct and indirect determinants to behavior. In extending the TRA, the determinants of behaviour are behavioural intention, facilitating conditions and user readiness to adopt new innovation. The direct determinants of people's behavioural intentions are their attitudes towards performing the behaviour, awareness of innovation, social pressure (networks and interactions), and the subjective norms associated with the behaviour. While attitude is determined by a person's beliefs about the outcomes or attributes of performing a specific behaviour, weighted by evaluations of those outcomes or attributes, the subjective norm of a person is determined by whether important referents approve or disapprove of the performance of a behaviour (normative beliefs), weighted by the person's motivation to comply with those referents and the social pressure (networks and interaction) resulting from those individuals influencing the user directly or indirectly. Figure 2 illustrates the extended Theory of Reasoned Action.

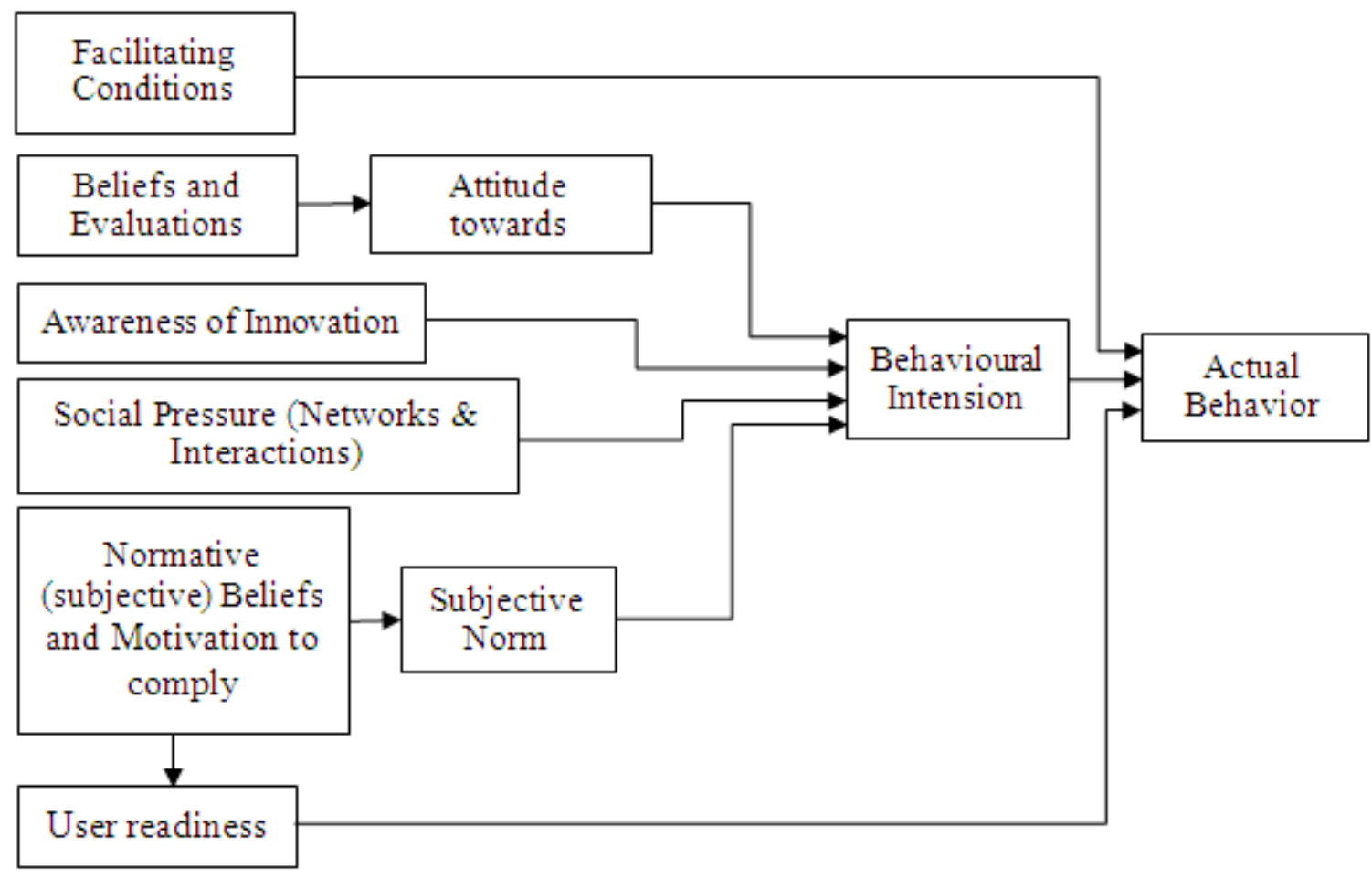

Source: Own conceptualization (2016)

Figure 2. Extended Theory of Reasoned Action 


\section{Conclusions}

In conclusion the TRA has been established to be a very strong theory over numerous models that have been used in technological innovation adoption studies. Adoption being an attitude issue, finds TRA as a strong theory, that with just a little modification, becomes sufficient to guide IS technological innovation adoption studies. The extension of the theory to include other variables like facilitating conditions, awareness of innovation, social pressure and user readiness to adopt, all improves TRA to better guide technological adoption and use studies. Further, this article contributes to theory by adopting theory of reasoned action (TRA) which is a social psychology theory into an IS study. Appropriate theories such as Fishbein and Ajzen's Theory of Reasoned Action could be expanded with other variables and employed in the relevant future studies which are also a contribution to theory.

\section{REFERENCES}

[1] Ajzen, I. \& Fishbein, M. (1980). Understanding Attitudes and Predicting Social Behavior. Englewood Cliffs, NJ, Prentice-Hall Inc.

[2] Fishbein, M. (1968). An investigation of relationships between beliefs about an object and the attitude towards that object. Human Relationships, 16, 233-240.

[3] Hoffmann, R. G., Rodrigue, J. R., \& Johnson, J. H. (1999). Effectiveness of a school-based program to enhance knowledge of sun exposure: Attitudes toward sun exposure and sunscreen use among children. Child Health Care, 28, 69-86.

[4] Ajzen, I. (1991). The theory of planned behavior. Organizational Behavior and Human Decision Processes, 50(2), 179-221.

[5] Wei, G., Xinyan, Z. \& Yue, M. (2011) Literature Review on Consumer Adoption Behavior of Mobile Commerce Services, International Conference on $\mathrm{E}$-Business and $\mathrm{E}$ - Government (ICEE) 1-5.

[6] Liker, J. K., \& Sindi, A. A., (1997). User acceptance of expert systems: a test of the theory of reasoned action. Journal of Engineering and Technology Management, Vol. 14, Issue 2, June 1997, Pages 147 - 173.

[7] Teo, T. S. H., \& Pok, S. H. (2003). Adoption of WAPenabled mobile phones among Internet users. Omega, 31, 483- 498 .

[8] McKemey, K. \& Saky-Dawson, O.A. (2000). Rice Crop Protection Technology Uptake Blockages amongst Rice Farmers in Ghana: with Particular Reference to Variety Adoption and the Reduction of Pesticide Use. Legon, Ghana, University of Legon, Ghana.

[9] Trafimow, D. \& Finaly, K. A., (2002). The prediction of attitudes from beliefs and evaluations: the logic of double negative. British Journal of Social Psychology, 41:77-86.

[10] Fishbein, M., \& Manfredo, M., J. (1992). A Theory of
Behavior Change. In M. Manfredo J (Ed.), Influencing Human Behavior: Theory and Applications in Recreation, Tourism, and Natural Resources Management (pp. 29-50). Champaign, Illinois: Sagamore Publishing Inc.

[11] Fishbein, M., \& Ajzen, I. (1975). Beliefs, attitude, intention, and behavior: An introduction to theory and research. Reading, MA: Addison-Wesley.

[12] Brown, S. A., Massey, A. P., Montoya-Weiss, M. M., \& Burkman, J. R., (2002). Do I Really Have to? User Acceptance of Mandated Technology. European Journal of Information Systems, 11(4), 283-295.

[13] Bhattacherjee, A., \& Premkumar, G., (2004). Understanding Changes in Belief and Attitude toward Information Technology Usage: A Theoretical Model and Longitudinal Test. MIS Quarterly, 28(2), 229-254.

[14] Davis, F. D. (1989) "Perceived Usefulness, Perceived Ease of Use, and User Acceptance of Information Technology", MIS Quarterly (13)3, 319-342.

[15] Venkatesh, V. \& Davis, F. D., (2000) “A Theoretical Extension of the Technology Acceptance Model: Four Longitudinal Field Studies", Management Science (46)2, pp. 186-204.

[16] Lee, Y., Kozar, K. A., \& Larsen, K. R. T., (2003). The Technology Acceptance Model: Past, Present, and Future, Communications of the Association for Information Systems (12)50, 752-780.

[17] Yousafzai, S. Y., Foxall G. R., \& Pallister, J. G., (2007). Technology Acceptance: A Meta-Analysis of the TAM: Part 1", Journal of Modeling in Management (2) 3, 251-280.

[18] Benbasat, I. \& Barki. H., (2007). Quo Vadis, TAM? Journal of the Association for Information Systems (8)4, pp. 211-218.

[19] Whetten, D. A., (1989). What Constitutes a Theoretical Contribution? Academy of Management Review (14)4, 490495.

[20] Bagozzi, R. P., (2007). The Legacy of the Technology Acceptance Model and a Proposal for a Paradigm Shift, Journal of the Association for Information Systems (8)4, 244254.

[21] Rogers, E.M. (1995) Diffusion of innovations, Fourth Edition ed., New York, Free Press.

[22] Tornatzky, L. \& Fleischer, M. (1990). The process of technology innovation, Lexington, MA, Lexington Books.

[23] Starbuck, W.H. (1976) Organizations and their environments, Chicago, Rand McNally.

[24] Hage, J. (1980) Theories of organizations: Forms, process and transformation, New York, John Wiley \& Sons.

[25] Bacharach, S. B., (1989). Organizational Theories: Some Criteria for Evaluation, Academy of Management Review (14)4, 496-515.

[26] Ajzen, I., (2010). The Theory of Planned Behavior, Viewed from: http://www.people.umass.edu/aizen/tpb.html, on February 16, 2016.

[27] Montano, D. E. \& Kasprzyk, D. (2002). The theory of reasoned action and the theory of planned behaviour. In $\mathrm{K}$. Glanz, B. K. Rimer, \& F. M. Lewis (Eds.), Health behaviour and health education: Theory, research and practice (pp. 67 98). San Francisco: Jossey Bass. 